\title{
Vitamin C, a Key Factor in Post-extraction Healing? A Preliminary Study
}

\author{
MARIANA IOANA MIRON ${ }^{1}$, EDMOND CIORA ${ }^{1 *}$, LOREDANA BAITAR ${ }^{1}$, \\ ANCA TUDOR ${ }^{2}$, EMILIA OGODESCU ${ }^{3}$, DALIANA BOJOGA ${ }^{1}$, SORANA ROSU ${ }^{4}$, \\ RAMONA AMINA POPOVICI ${ }^{*}$, CARMEN TODEA ${ }^{1}$
}

${ }^{1}$ Victor Babes University of Medicine and Pharmacy, Department of Oral Rehabilitation and Dento-periodontal Emergencies, School of Dentistry, 2 Eftimie Murgu Sq., 300041, Timisoara, Romania

${ }^{2}$ Victor Babes University of Medicine and Pharmacy, Department of Functional Sciences, Centre for Modeling Biological Systems and Data Analysis, 2 Eftimie Murgu Sq., 300041, Timisoara, Romania

${ }^{3}$ Victor Babes University of Medicine and Pharmacy, Faculty of Dentistry, Department of Paediatric Dentistry, 2 Eftimie Murgu Sq., 300041, Timisoara, Romania

${ }^{4}$ Grigore T. Popa University of Medicine and Pharmacy, Faculty of Dental Medicine, Department of Community Dentistry, 16 Universitatii Str., 700115, Iasi, Romania

${ }^{5}$ Victor Babes University of Medicine and Pharmacy, Faculty of Dentistry, Department of Oral Health and Management, 2 Eftimie Murgu Sq., 300041, Timisoara, Romania

Abstract: In clinical practice, after dental extraction, the main objective is the healing of the postextraction wound, without complications and in the shortest time possible. According to specialized studies, the defense and regeneration mechanisms of the body are in direct correlation with the plasmatic level of some vitamins, mainly vitamin $C$, which is directly involved in the repair of damaged tissues. The purpose of the present study was to evaluate the healing of the post-extraction wound in the conditions of oral administration of vitamin $C$, according to a predetermined administration protocol, as compared to the healing process under conventional conditions. Five volunteers were included in the study, who presented two teeth with indication of extraction, one of the extractions being performed under the conditions of administration of vitamin $C$. The evolution of the healing of the post-extraction wounds was assessed comparatively. The examination was done with the help of photographic examination by directly measuring the vestibulo-oral dimensions of the wounds using the digital micrometer and by recording the blood microcirculation at the level of the alveolar wound using the laser Doppler flowmetry. The level of vitamin $C$ in the tissues was also determined, using the lingual test for vitamin $C$, a simple and non-invasive method that uses the reagent 2.6 dichlorophenolindophenol. The results of the preliminary study show that the evolution and healing of the postextraction wound is accelerated under the conditions of vitamin $C$ administration, with regard to the administration protocol used in the study and compared to the healing situation under classical conditions. It can be stated that the human body consumes higher amounts of ascorbic acid in the case of dental extractions therefore the administration of vitamin $C$ is a necessity if a faster healing of their post-extraction wounds is desired.

Keywords: vitamin C, dental extraction, laser Doppler flowmetry, post-extraction wound.

\section{Introduction}

Vitamin $\mathrm{C}$ - acid ascorbic is a water-soluble organic substance, an essential micronutrient that serves as a co-factor in many enzymatic and chemical reactions. The name of vitamin $\mathrm{C}$-ascorbic acid is derived from the Latin, meaning "without scurvy." Because humans do not produce vitamin C, it has to be supplied from other sources such as fruit, vegetables and plant foods. In 1907, Axel Horst and Alfred Fröhlich suspected its existence on the basis of their research on guinea pigs. However the discoverer of vitamin $\mathrm{C}$ and rutin (sometimes called vitamin $\mathrm{P}$ ) was Albert Szent-Györgyi, who tried to isolate and purify the new substance with the reductive properties from citrus fruits, vegetables, and the adrenal glands. He was not sure of its properties and described it as a hydrocarbon with chemical formula C6H8O6. In 1926 Szent-Györgyi published his results and proposed a humorous name

\footnotetext{
*email: ciora.edmond@umft.ro,ramona.popovici@umft.ro
} 
"Ignose" from the words "I don't know" and the letters "ose" which characterizes sugars. On the editor's refusal who also rejected his next suggestion, "Godnose", Szent-Györgyi agreed to the proposition of naming the newly isolated substance "hexuronic acid". Szent-Györgyi and Svirbely published a work together on this subject in April 1932. Szent-Györgyi suspected the new substance to be vitamin $\mathrm{C}$ and along with another scientist, Norman Haworth, invented a new name for vitamin C, "ascorbic acid" [1].

Vitamin C is easily oxidized, participating in the redox systems of the body. It is essential for the synthesis of collagen, elastin, and cellular substance in the epithelium and also prevents the formation of excess free radicals. The impairment of collagen synthesis causes loss of skin firmness, the appearance of wrinkles, and capillary brittle-ness. Vitamin $\mathrm{C}$ determines healing of traumatic lesions and burns. It participates in the synthesis of tyrosine and phenylalanine and may affect pigment changes. Wound healing is one of the main challenges in dentistry because it can be a painful timeconsuming process and on the other hand, the quality of the healing dictates the evolution over time of the dento-periodontal and prosthetic restorations and implicitly, the quality of the patient's life. However, at present, the sphere of research regarding medication, dental materials, their physical, chemical and mechanical properties [2- 4], their effects on dento-periodontal tissues, as well as the methods of evaluation $[5,6]$, has greatly expanded. Wounds can be classified as acute or chronic. An acute wound occurs after either trauma or surgery and moves through the stages of the healing process. Wounds that have slow or non-healing tendency and do not follow the usual healing process are described as chronic wounds [7, 8]. Wound healing involves a series of complex stages that are influenced by the type and severity of the wound [7,9]. The stages of wound healing are: haemostasis, inflammation, reepithelialisation, neo-vascularisation, collagen deposition and matrix remodeling with scar formation. In this regard a high microbial load can severely diminish acute or chronic wound healing, which is especially challenging in the oral cavity $[8,10]$. When we discuss about oral wounds the most common is after tooth extraction. Intraoral wound healing occurs in an environment that sustains constant physical trauma and is rich in bacteria [11]. After a tooth is extracted, the dental alveoli (tooth sockets) are closed via blood clotting and re-epithelialization starts $24 \mathrm{~h}$ post-extraction [12]. It is important to mention that incisional wounds elicit a different response than excisional wounds, the second one healing at a slower rate, the case of tooth extraction [13]. According to the specialized literature, the defense and regeneration mechanisms of the body are in direct correlation with the plasmatic level of some vitamins, which compete in the repair process of damaged tissues [14, 15]. Vitamin $C$ is directly involved in the process of post-extraction healing by collagen synthesis [16, 17] and implicitly by the creation of neoformation networks in the blood clot through which circulation is enhanced [18, 19]. Because the human body cannot synthesize vitamin $\mathrm{C}$, the main source is from the consumption of fruits and vegetables. Vitamin $\mathrm{C}$ is considered to be well absorbed up to $500 \mathrm{mg} /$ day, although it seems that more than $500 \mathrm{mg} /$ day is needed for uncomplicated surgical patients and higher doses for severely stressed patients [17]. Considering these facts, the healing process after tooth extraction is an issue that needs to be assessed in order to develop new protocols that can accelerate and guide the post-extraction healing. Evaluating the development under vitamin $\mathrm{C}$ administration is important because it sustains the fact that it can improve and shorten the healing period. The aim of the study was to evaluate the healing of the post-extraction wound under the conditions of oral administration of vitamin $\mathrm{C}$, according to a predetermined schedule, compared to healing process under classical conditions.

\section{Materials and methods Patient selection}

The study included five adult volunteers, selected from the Oral Rehabilitation and Emergency in Dental Medicine Discipline, and the study was approved by the Local Ethics Commission. The subjects were in good general health, were non-smokers and presented at least 2 lateral teeth that were not recoverable from restorative point of view (following clinical and radiological examination), with 
indication of extraction. The teeth included in the study had no periapical complications, in acute phase. After informing the patients about the purpose of the study and the work protocol, the subjects gave their written consent to participate.

\section{Working protocol}

After consultation and signing the consent, patients were given oral hygiene instructions and the same toothpaste and mouthwash. For monitoring the nutrition, patients were given a table, showing the amounts of vitamin $\mathrm{C}$ contained in different foods, so they can consume the same categories of foods containing vitamin $\mathrm{C}$, in equal quantities, therefore, not to bring a different intake of vitamin $\mathrm{C}$ through nutrition during the study. This table is according to the one that appears on the website of the Ministry of Health, in the Guide for healthy eating, of the Nutrition Society of Romania. In the same session, impressions were taken of both areas selected for the experiment (the area of the teeth that were to be extracted), in order to make a LDF probe holder for immobilizing the laser Doppler probe. A condensation silicone Optosil Comfort Putty (heavy body) and Xantopren (light body) from Heraeus Kulzer was used. The sandwich type impression technique was performed, that covers two teeth adjacent to the tooth selected for extraction. After the probe holder decontamination, tunnels were created with a $1.5 \mathrm{~mm}$ drill on its vestibular side, in order to immobilize the laser Doppler probe. The tunnels were made perpendicular to the surface corresponding to the post extraction alveolus. The laser Doppler device calibration was performed according to the manufacturer's instructions, prior to every blood flow measurements. The determinations were made at 3, 7 and 10 days after extraction, for each subject included in the study.

In the second session, the first extraction was performed, according to the classic dental extraction protocol. Fifteen days after the first extraction, the patients came for the second extraction, which was performed according to the modified protocol, with oral administration of vitamin $\mathrm{C}$. The protocol for vitamin $\mathrm{C}$ administration was as follows: on the day of the extraction, patients were asked to orally take one vitamin $\mathrm{C}$ tablet $(500 \mathrm{mg}) 2 \mathrm{~h}$ before extraction, another tablet three hours after the intervention, and the third tablet in the evening. Oral administration of vitamin $\mathrm{C}$ was performed during seven days (on the day of extraction and six days after extraction), as follows: 500mg x 3 times/day. Therefore, 10 experimental sites were obtained where the healing process was monitored as follows: 5 post-extraction dental alveoli (after the first extraction), where healing process was happening without any intervention, the control group and 5 post-extraction dental alveoli that were healing in conditions of oral administration of vitamin C (500 mg tablets), the experimental group.

After performing the extractions no sutures were done, and in the dental alveoli there were no antibacterial or hemostatic materials applied, for example iodoform or sponges with vitamin $\mathrm{K}$. Patients, also received post-extraction recommendations for pain reduction and blood clot protection in order to have a healing without complications. The methods used to evaluate the post-extraction wound healing process were the following:

- direct measurement of the vestibulo-oral dimensions of the post-extraction wound dehiscence using the $0.01 \mathrm{~mm}$ sensitive digital micrometer. Consequently, the evolution of changes in the vestibulo-oral dimensions of the post-extraction dental alveoli was followed clinically. The measurement consisted in determining the length of the tangent taken to the oral and vestibular margins through the center of the wound; the center of the wound being represented by the intersection of the diagonals traced from the oral face to the vestibular one, of the teeth adjacent to the extracted one. The evolution of post-extraction healing was subsequently recorded and analyzed. Measurement of wound dehiscence was performed 3, 7 and 10 days after each tooth extraction (Figure 1 and Figure 2). 


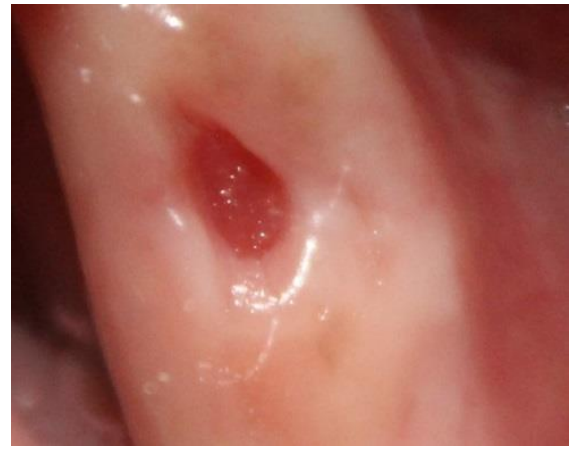

Figure 1. Post-extraction wound healing

at 7 days with vitamin $\mathrm{C}$ administration

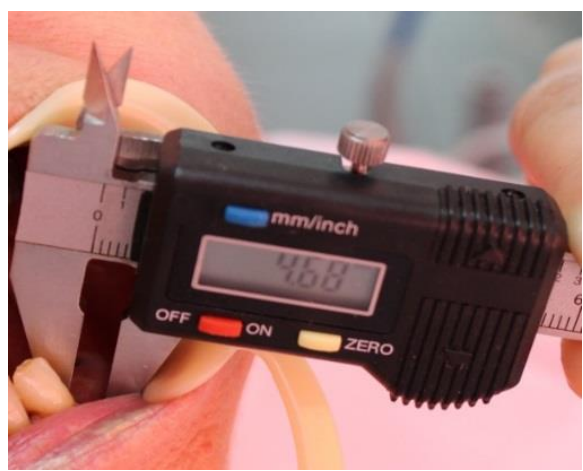

Figure 2. Dimension of the wound 7 days after extraction with vitamin $\mathrm{C}$ administration

Determination of the microcirculation dynamics at the level of the post-extraction alveolar wound used laser Doppler flowmetry. The laser Doppler device used was a MoorLab, moor VMS-LDF2, for which special optical fiber samples were purchased (MP3 1.5mm diameter, 10mm optical fiber length, $0.5 \mathrm{~mm}$ fiber separation), that are accredited by the manufacturer for dental use. The vestibular gingival margin of the alveolar wound has been tested for assessing the evolution of the gingival blood flow by using an adequate work technique [20, 21, 22, 23]. Laser Doppler probe was positioned on the middle of the vestibular margin of the post-extraction wound and the gingival blood flow (GBF) values were recorded for 1 minute. The amplitude (PU - perfusion units) and the presence of the pulsatile character of the laser Doppler path, recorded at the moments established according to the study design were of interest. These parameters highlight the presence and intensity of microcirculation in the gingival mucosa, in the healing process (Figure 3 ).

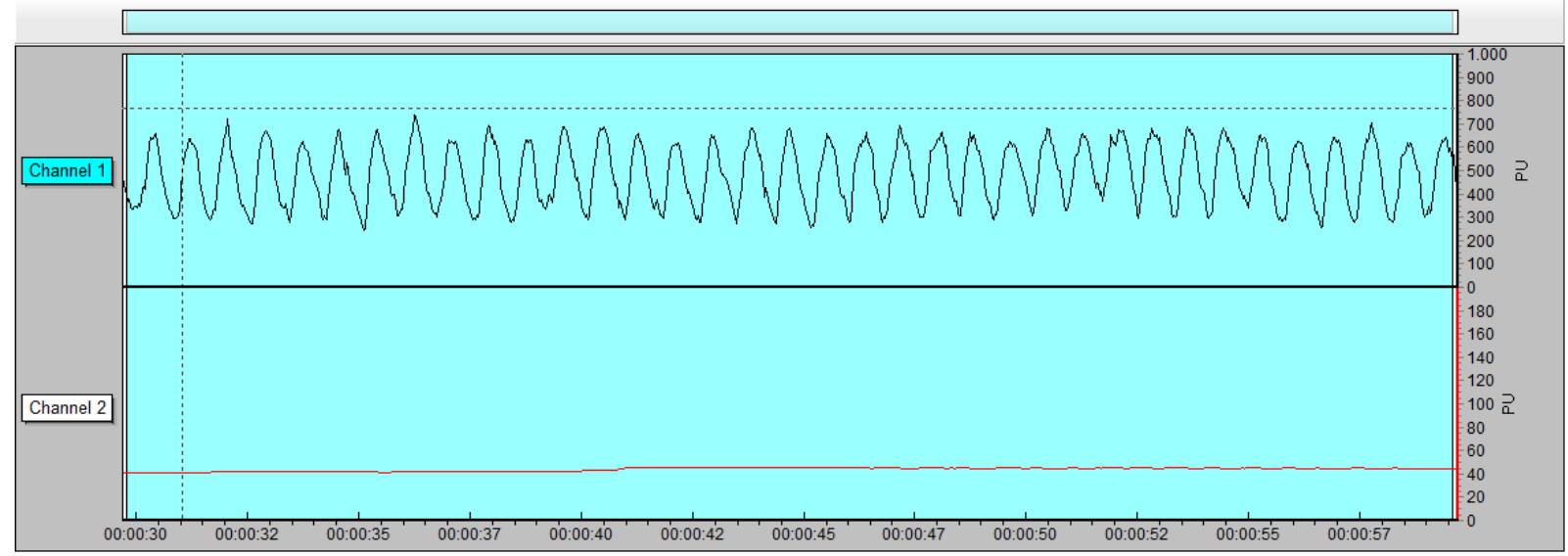

Figure 3. Laser Doppler signal 7 days after the extraction with vitamin $\mathrm{C}$ administration

The lingual vitamin C test (LAAT), a qualitative test, which uses the chromatographic technique and consisted of applying the 2.6 dichlorophenol-indophenol test solution on the dorsal side of the tongue. 
For the determination of the vitamin $\mathrm{C}$ present in the tissues, the lingual test for the determination of the vitamin $\mathrm{C}$ was performed, with the test solution 2.6 dichlorophenol-indophenol $(0.025 \mathrm{~g}$ powder 2.6 dichlorophenol-indophenol $\times 100 \mathrm{~mL}$ distilled water). Vitamin $\mathrm{C}$ (ascorbic acid) is a powerful antioxidant having the ability to reduce the reagent 2.6 dichlorophenol-indophenol. The test solution was obtained by dissolving $0.025 \mathrm{~g}$ of 2.6 dichlorophenol-indophenol powder with $100 \mathrm{~mL}$ of distilled water. The solution was prepared the day before extraction and kept cold and in a dark place. For this determination, the tongue was dried with a sterile compress, after that the taste buds, from the anterior third, on the dorsal side of the tongue were stimulated by light massage with a compress. A drop of test solution was applied on the tongue using a pipette and the blue to pink color shift timing was measured (Figure 4), this represents the reaction time between 2.6 dichlorophenol-indophenol and vitamin $\mathrm{C}$ from the tested organism. The higher the amount of vitamin $\mathrm{C}$ in the body, the shorter the reaction time and the blue color will disappear faster.
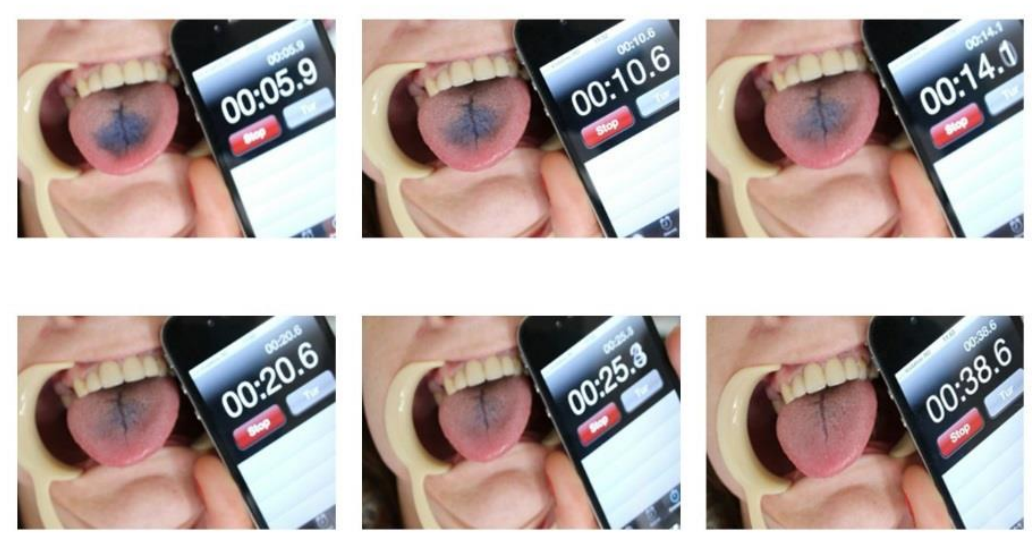

Figure 4. Lingual test for vitamin C

The test was performed at 3, 7 and 10 days after extraction and the results were interpreted as follows:

$<20 \mathrm{~s}-$ there is sufficient vitamin $\mathrm{C}$ at tissue level;

$>20 \mathrm{~s}$ - there is not enough vitamin $\mathrm{C}$ at tissue level.

\section{Results and discussions}

Table 1 show the dimensions of the post-extraction wounds, which were obtained after the direct measurement by using a $0.01 \mathrm{~mm}$ sensitive digital micrometer, as well as the healing percentage of the wound.

Table 1. The dimensions of the post-extraction wounds and the healing process

\begin{tabular}{|c|c|c|c|c|c|}
\hline & \multirow{2}{*}{ Case } & \multicolumn{3}{|c|}{ Wound size (mm) } & \multirow{3}{*}{$\begin{array}{c}\text { Healing \% } \\
5.4\end{array}$} \\
\hline & & after 3 days & after 7 days & after 10 days & \\
\hline \multirow{2}{*}{1} & Classic 2.5 & 8.96 & 8.62 & 8.50 & \\
\hline & Vitamin C 2.4 & 14.36 & 13.25 & 10.61 & 26.48 \\
\hline \multirow{2}{*}{2} & Classic 3.4 & 6.09 & 5.67 & 4.68 & 23.16 \\
\hline & Vitamin C 3.5 & 5.80 & 3.08 & 2.74 & 52.76 \\
\hline \multirow{2}{*}{3} & Classic 4.7 & 18.81 & 10.71 & 8.58 & 54.39 \\
\hline & Vitamin C 3.6 & 7.07 & 2.39 & 2.12 & 70.12 \\
\hline \multirow{2}{*}{4} & Classic 4.5 & 4.41 & 3.79 & 1.84 & 58.18 \\
\hline & Vitamin C 3.5 & 4.96 & 3,71 & 0 & 100 \\
\hline \multirow{2}{*}{5} & Classic 4.7 & 15.21 & 9.23 & 6.76 & 55.55 \\
\hline & Vitamin C 3.6 & 12.17 & 6.04 & 3.98 & 70.59 \\
\hline
\end{tabular}


Figure 5 shows a diagram of post-extraction wound healing process with and without vitamin $\mathrm{C}$ administration.

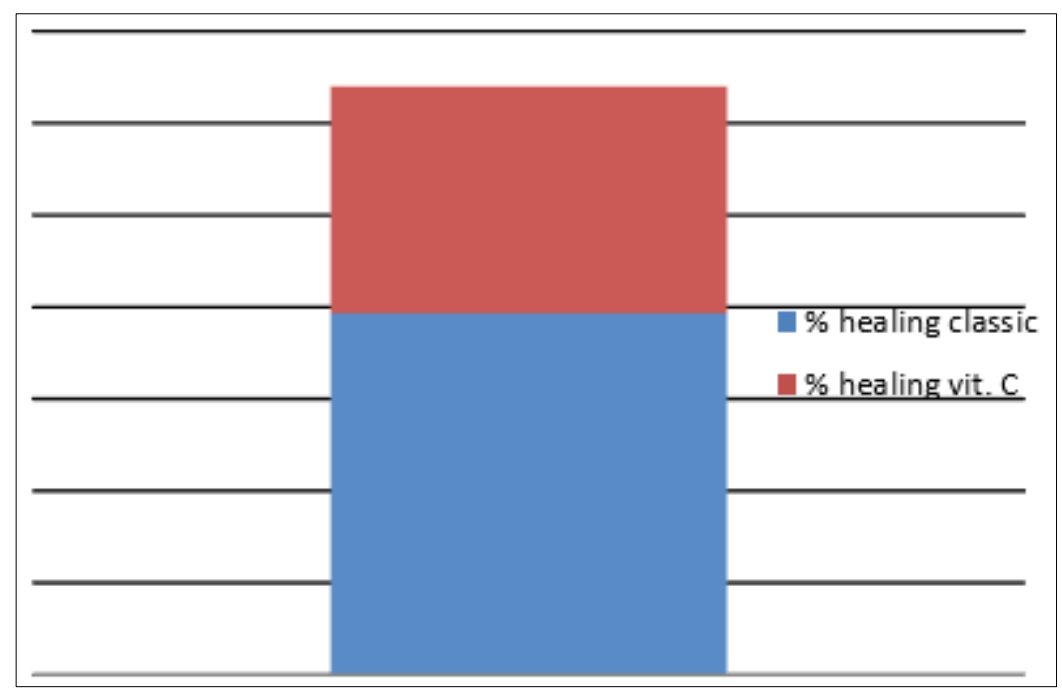

Figure 5. Diagram of post-extraction wound healing with and without vitamin $\mathrm{C}$

The values obtained from signal acquisition of GBF for the three moments of time (at 3 days, at 7 days and at 10 days after extraction) in both experimental conditions (with and without vitamin C) are shown in Table 2.

Table 2. Laser Doppler recorded gingival blood flow (GBF) mean values (PU) at 3 days, 7 days and 10 days after extraction

\begin{tabular}{|c|c|c|c|c|}
\hline \multirow{2}{*}{\multicolumn{2}{|c|}{ Case }} & \multicolumn{3}{c|}{ GBF mean values (PU) } \\
\cline { 2 - 5 } \multirow{2}{*}{1} & after 3 days & after 7 days & after 10 days \\
\cline { 2 - 5 } & Classic 2.5 & 110.5 & 141.6 & 395.8 \\
\hline \multirow{2}{*}{2} & Vitamin C 2.4 & 393.4 & 403.2 & 467.8 \\
\cline { 2 - 5 } & Classic 3.4 & 303.3 & 368,8 & 438 \\
\hline \multirow{2}{*}{3} & Vitamin C 3.5 & 193.7 & 493.8 & 244.2 \\
\cline { 2 - 5 } & Classic 4.7 & 416.8 & 526.4 & 130.3 \\
\hline \multirow{2}{*}{4} & Vitamin C 3.6 & 114.2 & 214.1 & 78.2 \\
\cline { 2 - 5 } & Classic 4.5 & 245 & 271.2 & 322.8 \\
\hline \multirow{2}{*}{5} & Vitamin C 3.5 & 222.1 & 366.7 & 369.8 \\
\cline { 2 - 5 } & Classic 4.6 & 305.9 & 353.22 & 411.3 \\
\hline \multirow{2}{*}{} & Vitamin C 3.6 & 229.7 & 372.3 & 422.9 \\
\hline
\end{tabular}

Figure 6 is the graphical representation of the GBF (mean values) recorded with laser Doppler flowmetry, according with the study design conditions and testing moments. 


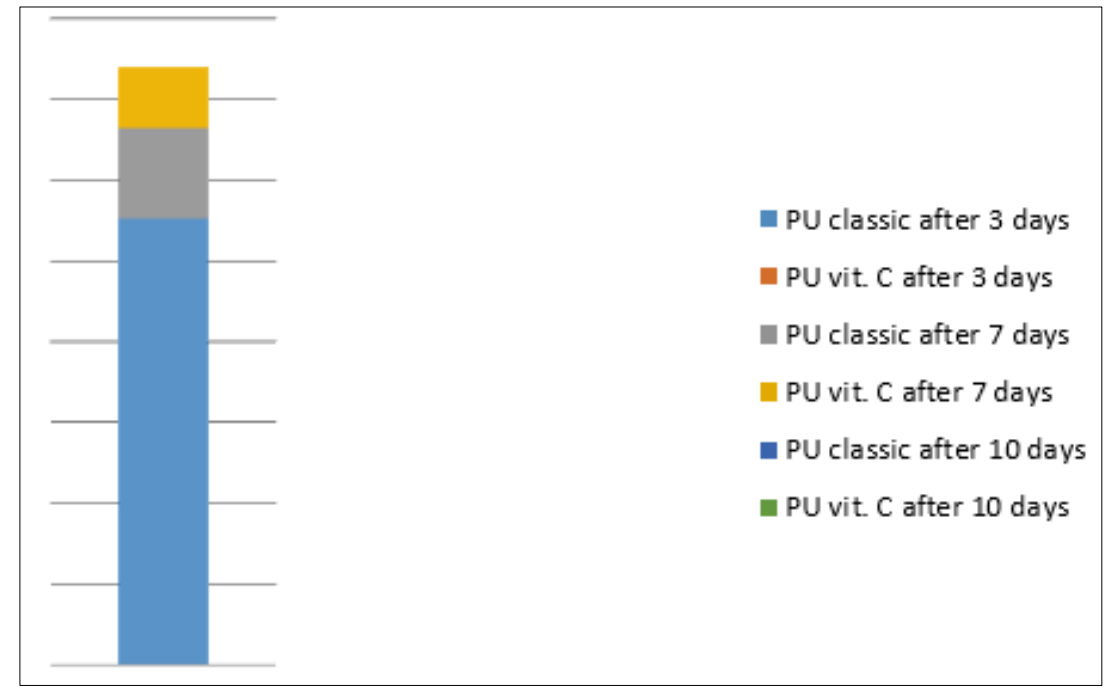

Figure 6. Diagram of laser Doppler recorded values

Table 3 shows the reaction time between 2.6 dichlorophenol-indophenol and vitamin $\mathrm{C}$, in the two experimental conditions, the higher the vitamin $\mathrm{C}$ concentration in the body, the shorter the reaction time.

Table 3. Reaction time (seconds) between

2.6 dichlorophenol-indophenol and vitamin C

\begin{tabular}{|c|c|c|c|c|}
\hline & \multirow[t]{2}{*}{ Case } & \multicolumn{3}{|c|}{$\begin{array}{l}\text { Reaction time between } 2.6 \text { dichlorophenol- } \\
\text { indophenol and vit. } \mathrm{C} \text { (seconds) }\end{array}$} \\
\hline & & After 3 days & la 7 zile & la 10 zile \\
\hline \multirow{2}{*}{1} & Classic 2.5 & 62 & 55 & 46 \\
\hline & Vitamin C 2.4 & 51 & 30 & 21 \\
\hline \multirow{2}{*}{2} & Classic 3.4 & 129 & 20.1 & 15.7 \\
\hline & Vitamin C 3.5 & 29.9 & 17.9 & 11.9. \\
\hline \multirow{2}{*}{3} & Classic 4.7 & 31.4 & 29.7 & 37.4 \\
\hline & Vitamin C 3.6 & 16.0 & 14.3 & 11.7 \\
\hline \multirow{2}{*}{4} & Classic 4.5 & 53.5 & 34.0 & 23.8 \\
\hline & Vitamin C 3.5 & 48.3 & 32.7 & 17.0 \\
\hline \multirow{2}{*}{5} & Classic 4.6 & 44 & 32 & 23 \\
\hline & Vitamin C 3.6 & 31 & 19 & 14 \\
\hline
\end{tabular}

Figure 7 shows the diagram of the results obtained after performing the lingual test to vitamin $\mathrm{C}$, in the three evaluation moments.

Use of high dose of vitamin $\mathrm{C}$ has been estimated to be beneficial for many conditions, being recommended by many authors [24 - 29]. For example the Evidenced Based Guidelines for Type 1 complex regional pain syndrome (CRPS) for wrist fracture suggested an intervention which consists of daily $500 \mathrm{mg}$ dose of vitamin $\mathrm{C}$ for 50 days [30]. Based on the assumption that vitamin $\mathrm{C}$ plays an essential role in the healing of any wound, whether surgical or accidental, the present study aimed to evaluate whether ascorbic acid enhances post-extraction wound healing. The evaluation of postextraction wound healing was performed according to the predetermined working protocol, recording values of the dimensions of the post-extraction wound, gingival blood flow (GBF) microdynamics values $[22,23]$ and values of the lingual test for vitamin $\mathrm{C}$, as well as clinical results. 


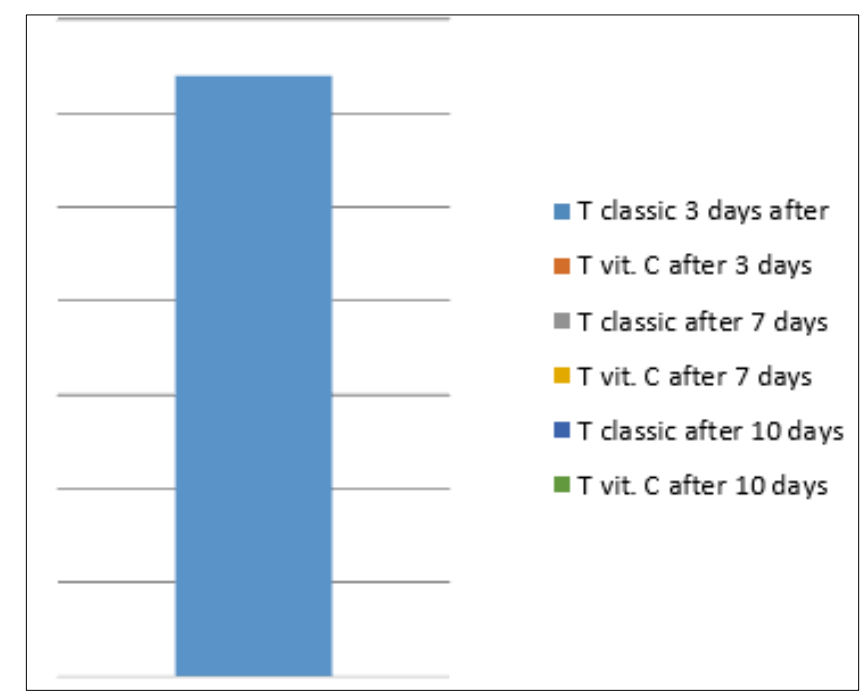

Figure 7. Diagram of the lingual test for vitamin C

Following the comparisons of the intraoral photos obtained after the photographic examination, there is a healing of all post-extraction wounds, but it can be stated that in the case of the patients being administered vitamin $\mathrm{C}$, the healing was accelerated, a result visible from the third day after extraction.

The white fibrin clot, present above the post-extraction wound, is more visible on the third day in both cases. On the seventh day, the white clot disappears from the wounds where vitamin $\mathrm{C}$ was administered and on those where the classical protocol of dental extraction was respected, it still persists. On the tenth day, the white fibrin clot disappears from all post-extraction wounds, in both cases.

The results obtained show that in the case of all post-extraction wounds (with vitamin $\mathrm{C}$ and the classic ones) there is a healing, but in different percentages, the higher healing percentage being in favor of the group where vitamin $\mathrm{C}$ was administered.

According to the results from the Table 1, in the first case there is a healing percentage difference of $21.08 \%$ in favour of extraction with vitamin $\mathrm{C}$ administration; in the second case, 29.6\%; in the third, $15.73 \%$; in the fourth, $41.82 \%$, and in the fifth, $15.04 \%$. The average percentage of classical healing was 39.64, and the one with vitamin $\mathrm{C}$ administration was 63.99 , the average percentage difference between post-extraction healing with vitamin $\mathrm{C}$ and the classic one being 24.65 percent. The maximum value of wound healing, in percentages, in the case of classical healing, was $58.18 \%$, and the minimum $5.4 \%$.

In the case of healing under oral administration of vitamin $\mathrm{C}$, the maximum percentage of healing was $100 \%$ and the minimum value was $26.48 \%$. In all five cases, there is a decrease in the size of the post-extraction wounds, both in the case of the administration of vitamin $\mathrm{C}$ and in the classical one. However, it can also be observed that in the case of oral vitamin $\mathrm{C}$ administration, the decrease is faster, which suggests a faster healing.

The results obtained from the direct measurement of the dehiscence of the post-extraction wounds, with the help of the digital micrometer, show a greater healing percentage in the case of oral administration of vitamin $\mathrm{C}$ compared to the classic dental extraction. These observations show that there is a direct correlation between oral vitamin $\mathrm{C}$ administration and the post-extraction healing process.

Laser Doppler recorded signals did not show the pulsatile character 3 days after extraction, in both experimental conditions. However, the pulsatile signals registered on the seventh day in the situation in which the vitamin $\mathrm{C}$ was administrated and on the tenth day in the wounds that healed according to the classical protocol. If we consider the amplitude of the signal it can be observed that in the case of 
healing according to the classical protocol, the mean value of the perfusion units follows a slowly rising curve along the three determinations (day 3- 276.3; day 7- 332.244; day 10-339.64). In contrast to the control group, in the experimental situation i.e. when the vitamin $\mathrm{C}$ was administered, a lower mean value of the perfusion units was observed on the third day (230.62 PU), then, on the seventh day the highest values were recorded $(370.02 \mathrm{PU})$ which coincides with the date when the pulsatile character of the signal was recorded.

This fact suggests an accelerated wound healing process when the vitamin $\mathrm{C}$ was administrated, by the appearance of microcirculation with a pulsatile character at this level.

According with the results of our study it can be pointed out that ten days are not enough for examining the evolution of the total healing process of the soft tissues injured after the dental extractions. In the case of vitamin $\mathrm{C}$ administration, following laser Doppler recordings, we can ask the question whether the time allocated to the study was insufficient or the doses of vitamin $\mathrm{C}$ administered were insufficient?

Regarding the time of disappearance of the blue colour of 2.6 dichlorophenol-indophenol solution, from the lingual test for vitamin $\mathrm{C}$, the results were presented in table number 3 . From the results obtained from the lingual testing of vitamin $\mathrm{C}$, it can be observed that in both cases (classic and with vitamin $\mathrm{C}$ administration), on the third day after the extraction the colour disappearance time increases significantly compared to the reference value of $20 \mathrm{~s}$, which shows that the body consumes higher amounts of vitamin $\mathrm{C}$ in the case of wounds.

At seven days and ten days post-extraction, there is a decrease in the time of colour disappearance in both cases, so the vitamin $\mathrm{C}$ requirement of the body is in direct correlation with the size of the postextraction wound.

In the case of classical treatment, at 3 days post-extraction, all the five patients exceeded the limit of $20 \mathrm{~s}$ (the first with $42 \mathrm{~s}$; the second with $109 \mathrm{~s}$; the third with 11.4; the fourth with $33.5 \mathrm{~s}$; the fifth with $24 \mathrm{~s}$ ). At 7 days post-extraction, at four of the five patients the limit of $20 \mathrm{~s}$ was exceeded (the first with $35 \mathrm{~s}$; the third with 9.7; the fourth with 14 seconds; the fifth with $12 \mathrm{~s}$ ). The second patient exceeded the $20 \mathrm{~s}$ limit insignificantly, by $0.1 \mathrm{~s}$. At 10 days after the extraction performed according to the classical protocol, four of the five patients exceeded the $20 \mathrm{~s} \mathrm{limit}$ of disappearance of colour, two of the four with very low values (the first with $26 \mathrm{~s}$; the third with 7.4; the fourth with $3.8 \mathrm{~s}$; the fifth with $3 \mathrm{~s}$ ).

In the case of extraction with oral administration of vitamin $C$, at 3 days post-extraction, only four of the five patients exceeded the limit of $20 \mathrm{~s}$ to disappearance of the 2.6 dichlorophenol-indophenol solution coloration (the first with 31 seconds; the second with 9,9; the fourth with $28.3 \mathrm{~s}$; the fifth with $11 \mathrm{~s})$. At 7 days after extraction, only two patients exceeded the limit (the first one by $10 \mathrm{~s}$ and the fourth by 12.7), and at 10 days after extraction only the first patient exceeded insignificantly (1 second) the limit of $20 \mathrm{~s}$.

The maximum value of the disappearance time of the colour of the reagent was on the third day after the dental extraction, performed after the classical protocol (129 s). In the case of dental extractions performed under vitamin $\mathrm{C}$ administration, the maximum value was $51 \mathrm{~s}$, also on the third post-extraction day, which highlights that the vitamin $\mathrm{C}$ requirement in the oral tissues increases in the first days after extraction. Although the values of the colour disappearance decrease in the case of the administration of vitamin $\mathrm{C}$, for all the patients, the used dosage of vitamin $\mathrm{C}$ orally administered was not sufficient, fact exposed by the lingual test for vitamin $\mathrm{C}$.

At the same time, we can observe that the body uses higher amounts of ascorbic acid after the dental extractions, which are necessary in the healing process. These results are consistent with those obtained in other specialized studies [16-19, 24 - 32].

\section{Conclusions}

The results of this preliminary study show that vitamin $\mathrm{C}$ contributes to the healing of the postextractional wound and also to the resumption of a normal microcirculation in the traumatized tissues. 
The data obtained from the comparative assessments showed a positive evolution of the postextractional wounds, in accordance with the oral administration of vitamin C.

It can also be concluded that the human body consumes higher amounts of ascorbic acid in the case of dental extractions, so we can say that the administration of vitamin $\mathrm{C}$ is a necessity if a faster healing of post-extraction wounds is desired. Moreover, we can say that the vitamin $\mathrm{C}$ requirement at tissue level is directly proportional to the wound size and the healing time required.

Given that the study was conducted on a small sample of patients, it is necessary to evaluate further on larger samples. If the results will be confirmed in studies with larger samples, it is necessary to determine an adequate protocol for administration of vitamin $\mathrm{C}$ for a more efficient and accelerated post-extractional wound healing process.

\section{References}

1.GRZYBOWSKI, A., PIETRZAK, K. ALBERT SZENT-GYÖRGYI (1893-1986): The scientist who discovered vitamin C.,Volume 31, Issue 3, May-June 2013, Pages 327-331.

2.MARTHA, K., OGODESCU, A., ZETU, I. The Effect of Phosphoric Acid Etching Application Time on the Enamel Morphology - a Comparative SEM Study, Rev. Chim., 64 (9), 2013, 982-986.

3.OGODESCU, A. S., MORVAY, A. A., BALAN, A. Comparative Study on the Effect of Three Disinfection Procedure on the Streptococcus pyogenes Biofihn Formed on Plastic Materials Used in Paedodontics and Orthodontics, Mater. Plast., 54 (1), 2017, 116-118.

4.MARTHA, K., OGODESCU, A., ZETU, I. Comparative in vitro Study of the Tensile Bond Strength of Three Orthodontic Bonding Materials, Mater. Plast., 50 (3), 2013, 208-211.

5.OGODESCU, A.S., SINESCU C., OGODESCU E.A., NEGRUTIU M., ROMINU R., BRATU E. Computer Science in the Orthodontic Treatment of Adults, Advances in Communications, Computers, Systems, Circuits and Devices, 2010.

6.OGODESCU E., OGODESCU A., SINESCU C., SZABO K., BRATU E. Biology of Dento-facial Growth and Development: Updating Standards using Digital Imaging Technologies, Advances in Biology, Bioengineering and Environment, 2010.

7.SHAH, S. A., SOHAIL, M., KHAN, S., MINHAS, M. U., DE MATAS, M., SIKSTONE, V., HUSSAIN, Z., ABBASI, M., KOUSAR, M. Biopolymer-based biomaterials for accelerated diabetic wound healing: A critical review, International Journal of Biological Macromolecules, 2019; 139: 975-993.

8.HEHER, P., MÜHLEDER, S., MITTERMAYR, R., REDL, H., SLEZAK, P. Fibrin-based delivery strategies for acute and chronic wound healing, Advanced Drug Delivery Reviews, 2018; 129, 134147.

9.VOSS, G.T., GULARTE, M.S., VOGT, A.G., GIONGO, J.L., VAUCHER, R.A., ECHENIQUE, J.V.Z., SOARES, M.P., LUCHESE, C., WILHELM, E.A., FAJARDO, A.R. Polysaccharide-based film loaded with vitamin $\mathrm{C}$ and propolis: A promising device to accelerate diabetic wound healing. International Journal of Pharmaceutics, 2018; 552: 340-351.

10.YOUNG A., MCNAUGHT, C.E. The physiology of wound healing. Surgery (Oxford), 2011; 29(10): 475-479.

11.XIAOYING KONG, JUN FU, KAI SHAO, LILI WANG, XUEFANG LAN, JINSHENG SHI. Biomimetic Hydrogel for Rapid and Scar-free Healing of Skin Wounds inspired by the healing process of oral mucosa. Acta Biomaterialia, 2019; doi: https://doi.org/10.1016/j.actbio.2019.10.011

12.LARJAVA, H. Oral Wound Healing: Cell Biology and Clinical Management, 2012, West Sussex: John Wiley \& Sons, Inc.

13.HARRISON, J.W. Healing of surgical wounds in oral mucoperiosteal tissues, Journal of Endodontics, 1991; Volume 17, Issue 8, Pages 401-408. 
14.MIN SU, XIAOLIU LIANG, XIAOXIAO XU, XINMOU WU, BIN YANG. Hepatoprotective benefits of vitamin $\mathrm{C}$ against perfluorooctane sulfonate-induced liver damage in mice through suppressing inflammatory reaction and ER stress. Environmental Toxicology and Pharmacology, 2019; Volume 65(1): 60-65.

15.HININGER, I., WATERS, R., OSMAN, M., GARREL, C., ANDERSON R. A. Acute prooxidant effects of vitamin $\mathrm{C}$ in EDTA chelation therapy and long-term antioxidant benefits of therapy. Free Radical Biology and Medicine, 2005; Volume 38, Issue 12, Pages 1565-1570.

16.DEPHILLIPO, N.N., AMAN, Z.S., KENNEDY, M.I., BEGLEY, J.P., MOATSHE, G., LAPRADE, R.F. Efficacy of Vitamin C Supplementation on Collagen Synthesis and Oxidative Stress After Musculoskeletal Injuries: A Systematic Review. Orthopaedic Journal of Sports Medicine, 2018; 6(10): 232596711880454. doi:10.1177/2325967118804544

17.FUKUSHIMA, R., YAMAZAKI, E. Vitamin C requirement in surgical patients. Current Opinion in Clinical Nutrition and Metabolic Care, 2010; 13(6):669-676. doi:10.1097/mco.0b013e32833e05bc 18.TOFLER, G.H., STEC, J.J., STUBBE, I., BEADLE, J., FENG, D., LIPINSKA, I., TAYLOR, A. The effect of vitamin $\mathrm{C}$ supplementation on coagulability and lipid levels in healthy male subjects. Thromb Res, 2000; 100(1):35-41.

19.BIKKER, A., WIELDERS, J., VAN LOO, R., LOUBERT, M. Ascorbic acid deficiency impairs wound healing in surgical patients: Four case reports, International Journal of Surgery Open, 2016; Volume 2, Pages 15-18,

20.TODEA, C., CÂNJĂU, S., MIRON., S, VITEZ, B., NODIȚI, G. Chapter 9, Laser Doppler Flowmetry Evaluation of the Microcirculation in Dentistry in Microcirculation Revisited- From Molecules to Clinical Practice, Edited by Helena Lenasi, ISBN 978-953-51-2731-4, Print ISBN 978953-51-2730-7, Publisher InTech, Chapters published October 26, 2016 under CC BY 3.0 license; pp. 203 - 230. DOI: $10.5772 / 61893$.

21.CANJAU, S., MIRON, MI., TODEA, D.C. Assesment of gingival microcirculation in anterior teeth using laser Doppler flowmetry, Proc. SPIE 9670, Sixth International Conference on Lasers in Medicine, 2016, 96700E, doi:10.1117/12.2191426.

22.CÂNJĂU, S., MIRON, M.I., TODEA, D.C. Laser Doppler Flowmetry Evaluation of Gingival Microcirculation Recovery in Gingivitis, Archives of the Balkan Medical Union, 2015; vol. 50, no. 3, pp. 354 - 359, http://www.balkanmedicalunion.com/en/article/laser-doppler-flowmetry-evaluation-ofgingival-microcirculation-recovery-in-gingivitis_full-text

23.PETRE, L.C., MIRON, M.I., IANES, E. Laser Doppler flowmetry: an early diagnosis instrument in detecting the soft tissue changes that occur during radiotherapy to the head and neck area, clinical case report, Proc. SPIE 9670, Sixth International Conference on Lasers in Medicine, 2016; doi:10.1117/12.2191426, http://spie.org /Publications/Proceedings/Paper/10.1117/12.219 1426

24.SHIBUYA, N., HUMPHERS, J.M., AGARWAL, M.R., JUPITER, D.C. Efficacy and Safety of High-dose Vitamin C on Complex Regional Pain Syndrome in Extremity Trauma and Surgery Systematic Review and Meta-Analysis, The Journal of Foot \& Ankle Surgery, 2013; 52, 62-66.

25.OHNO, S., OHNO Y., SUZUKI, N., SOMA, G., INOUE, M. High-dose vitamin C (ascorbic acid) therapy in the treatment of patients with advanced cancer. Anticancer Res, 2009; 29(3):809-815;

26.SUH, S.Y., BAE, W.K, AHN, H.Y., CHOI, S.E., JUNG, G.C., YEOM, C.H. Intravenous vitamin C administration reduces fatigue in office workers: a double-blind randomized controlled trial. Nutr J, 2012; 11:7, PMCID: 3273429.

27.ICHIM, T.E., MINEV, B., BRACIAK, T., LUNA, B., HUNNINGHAKE, R., MIKIROVA, N.A., JACKSON, J.A., GONZALEZ, MJ., MIRANDA-MASSARI, J.R., ALEXANDRESCU, D.T., DASANU, C.A., BOGIN, V., ANCANS, J., STEVENS, R.B., MARKOSIAN, B., KOROPATNICK, J, CHEN, C.S., RIORDAN, N.H. Intravenous ascorbic acid to prevent and treat cancer-associated sepsis? J Transl Med, 2011; 9:25, PMCID: 3061919. 
28.MOHAMMED, B.M., FISHER, B.J., KRASKAUSKAS, D., WARD, S., WAYNE, J.S., BROPHY, D.F., FOWLER, A.A. III., YAGER, D.R., NATARAJAN, R. Vitamin C promotes wound healing through novel pleiotropic mechanisms. Int Wound J, 2015; 13(4), 572-584.

doi: 10.1111/iwj.12484.

29.LANGLOIS, L.P., LAMONTAGNE, F. Vitamin C for the critically ill: Is the evidence strong enough?, Nutrition, 2019; Volume 60, Pages 185-190, ISSN 0899-9007, https://doi.org/10.1016/j. nut.2018.10.009.

30.ROSENBRAND, K.C., GEERTZEN, J.H. CRPS I Task Force. Evidence based guidelines for complex regional pain syndrome type 1. BMC Neurol, 2010; 10:20, PMCID: 2861029.

31.MEDERLE, N., MARIN, S., MARIN, M.M. et al. Innovative Biomaterials Based on CollagenHydroxyapatite and Doxycycline for Bone Regeneration, ADVANCES IN MATERIALS SCIENCE AND ENGINEERING, 2016; Article Number: 3452171, https://doi.org/10.1155/2016/3452171

32.NITIPIR, G.C., MARIN, S., MARIN, M.M., KAYA, M.A., GHICA, M.V., MEDERLE, N. Hybrid Collagen-NaCMC Matrices Loaded with Mefenamic Acid for Wound Healing, Rev. Chim., 68 (11), 2017, 2605-2609, https://doi.org/10.37358/RC.17.11.5938.

$\overline{\text { Manuscript received: } 13.04 .2020}$ 